\title{
Centaur VGI: a hybrid human-machine approach to address global inequalities in map coverage
}

DOI:

https://doi.org/10.1080/24694452.2020.1768822

Document Version

Accepted author manuscript

Link to publication record in Manchester Research Explorer

\section{Citation for published version (APA):}

Huck, J., Perkins, C., Haworth, B. T., Moro, E., \& Nirmalan, M. (2021). Centaur VGl: a hybrid human-machine approach to address global inequalities in map coverage. Annals of the Association of American Geographers, 111(1), 231-251. https://doi.org/10.1080/24694452.2020.1768822

\section{Published in:}

Annals of the Association of American Geographers

\section{Citing this paper}

Please note that where the full-text provided on Manchester Research Explorer is the Author Accepted Manuscript or Proof version this may differ from the final Published version. If citing, it is advised that you check and use the publisher's definitive version.

\section{General rights}

Copyright and moral rights for the publications made accessible in the Research Explorer are retained by the authors and/or other copyright owners and it is a condition of accessing publications that users recognise and abide by the legal requirements associated with these rights.

\section{Takedown policy}

If you believe that this document breaches copyright please refer to the University of Manchester's Takedown Procedures [http://man.ac.uk/04Y6Bo] or contact uml.scholarlycommunications@manchester.ac.uk providing relevant details, so we can investigate your claim.

\section{OPEN ACCESS}




\title{
Centaur VGI: a hybrid human-machine approach to address global inequalities in map coverage
}

\author{
Huck, J.J. ${ }^{1}$, Perkins, C. ${ }^{1}$, Haworth, B.T. ${ }^{2}$, Moro, E.B. ${ }^{3}$, Nirmalan, M. ${ }^{4}$ \\ ${ }^{1}$ MCGIS, Department of Geography, The University of Manchester, UK \\ ${ }^{2}$ MCGIS, Humanitarian and Conflict Response Institute, The University of Manchester, UK \\ ${ }^{3}$ Faculty of Medicine, Gulu University, Uganda \\ ${ }^{4}$ Faculty of Biology, Medicine and Health, The University of Manchester, UK
}

\begin{abstract}
Despite advances in mapping technologies and spatial-data capabilities, global mapping inequalities are not reducing. Inequalities in the coverage, quality and currency of mapping persist, with significant gaps in remote and rural parts of the Global South. These regions, representing some of the most economic and resource disadvantaged societies in the world, need high-quality mapping to aid in the delivery of essential services, such as healthcare, in response to severe challenges such as poverty, conflict, and global climate change. Volunteered geographical information (VGI) has shown potential as a solution to mapping inequalities. However, contributions have largely been made in urban areas or in response to acute emergencies (such as earthquakes or floods), leaving rural regions that suffer from chronic humanitarian crises under-mapped. An alternative solution is needed that harnesses the power of volunteer mapping more effectively to address regions in most need. Machine learning holds promise. In this paper we propose centaur VGI; a hybrid system that combines the spatial cognitive abilities of human volunteers with the speed and efficiency of a machine. We argue that centaur VGI can contribute to mitigating some of the political and technological factors that produce inequalities in VGI mapping coverage, and do so in the context of a case study in Acholi, northern Uganda; an inadequately mapped region in which the authors have been working since 2017 to provide outreach healthcare services to victims of major limb loss during conflict.
\end{abstract}




\section{Keywords}

VGI, Machine Learning, Mapping Inequalities, OpenStreetMap, Humanitarian Mapping

\section{Introduction}

Inequalities in the coverage, quality and currency of mapping persist, with significant gaps in remote and rural parts of the Global South that suffer from on-going chronic humanitarian crises. These areas in particular could benefit significantly were they able to implement National Spatial Data Infrastructures (SDI) in support of the UN 2030 Sustainable Development Goals (SDGs) - but Scott and Rajabifard (2017: 64) recognise that many developing nations currently "continue to face problems of poor data quality, lack of timely data and a lack of interoperability between different sources of data". Mapping is rarely explicitly discussed in policy fora, but is fundamental for SDI. Nor do these areas attract the same level of attention from humanitarian mapping volunteers as those with more acute emergencies (such as a serious disease outbreak or a significant natural hazard leading to a disaster or humanitarian crisis).

It has been suggested that volunteered geographic information (VGI) ${ }^{1}$ (Goodchild, 2007) might offer a potential solution for these kinds of regions. However, there are significant concerns from official sources regarding data quality, ownership and knock-on impacts on professional employment in the mapping sector (Oltenu-Raimond et al., 2017) and there is no guarantee that a given feature will ever be mapped (Hagenauer and Helbich, 2012). In addition, practical issues relating to volunteer motivation and the pragmatic combination of technologies have hindered widespread take up of VGI

\footnotetext{
${ }^{1}$ Volunteered Geographic Information refers to the widespread voluntary engagement of private citizens in the creation of online geographic information through technologies such as crowdsourced mapping, Web 2.0 and social media, global positioning systems (GPS), and smartphones (Haworth, 2016).
} 
for addressing mapping inequalities. Machine learning (ML) ${ }^{2}$ has already been widely deployed to automate aspects of the mapping process, and in particular in the field of extracting features from remotely sensed image data (Zhu et al., 2017). To date, however, advances in this area have focused on conceptual or technical challenges, instead of offering practical solutions that might be widely appropriate for rectifying inequalities in mapping.

In this paper we argue that VGI and ML might profitably be brought together to address motivational and practical issues in the mapping of remote rural areas of the Global South, and develop the notion of 'Centaur VGI' in support of this argument. In technology, the term 'centaur' describes a hybrid human/machine approach to accomplishing a task (Thompson, 2013). The term originated from 'centaur chess', a variation of the game in which grand masters collaborate with a machine to exploit the benefits of human intuition and the speed of computer players. This produces a synergy, whereby the result is better than could be achieved by each agent working separately (Thompson, 2013). We present an argument for the adoption of 'Centaur VGI', as a strategy to combine the object recognition and spatial cognitive skills of people with the speed and efficiency of a machine. We argue that such an approach could contribute to reducing some of the political and technological factors that together lead to inequalities in mapping coverage in many parts of the world. We describe a conceptual model for the development of this kind of system and situate this against case evidence from the Acholi sub-region of Uganda.

\section{Global Inequalities in Mapping}

\footnotetext{
${ }^{2}$ Machine Learning refers to computer systems that are capable of developing their own algorithms to solve complex problems (e.g. identifying features in imagery) by analysing input data (e.g. satellite imagery) and desired result (e.g. pre-defined features) for a given problem. This contrasts with traditional computing approaches, where the algorithm is provided to the computer in order to derive results from input data. (Domingues, 2017).
} 
Over the years, several attempts have been made to quantify variations in mapping at different scales including analyses at an international level (e.g. Perkins, 1987 and Parry and Perkins, 2000), regional level (e.g. Böhme et al., 1991) and more detailed and multi-method surveys of individual countries (e.g. Radcliffe, 2009). Variations in map coverage across the world have received particular attention from technical and official reviews, and professional bodies have vested interests in charting progress in their fields. International comparative metrics have been produced documenting an apparently inexorable advance in mapping (see for example Konecny et al, 2016). The International Cartographic Association (ICA) and the United Nations Committee of Experts on Global Geospatial Information Management (UN-GGIM) have undertaken periodic surveys on global map coverage, based upon self-reporting from each individual country (Konecny et al., 2016) ${ }^{3}$. These surveys suggest a gradual improvement and reduction in inequalities, with more of the globe covered at larger scales as scientific enterprise progresses. However, such approaches require countries to return responses to surveys and to provide robust and honest answers. In the case of the UN-GGIM study published by Konecny et al. (2016), for example, only 115 of the 193 UN member states (or regions thereof) responded to the survey $(59.6 \%)$, with the remaining national data $(40.4 \%)$ assembled from a selection of other sources including map dealers, libraries and personal correspondence. Many of the $>40 \%$ of countries who did not respond to the survey are located in the Global South (Figure 1). This implies that reported increases in mapping coverage since 1986 made by Konecny et al. (2016) may be biased towards mapping activity in the developed world and that true global figures are likely to be lower.

${ }^{3}$ An interactive map at: http://www.ipi.uni-hannover.de/StatusOfWorldMapping shows detailed responses to the latest survey. 


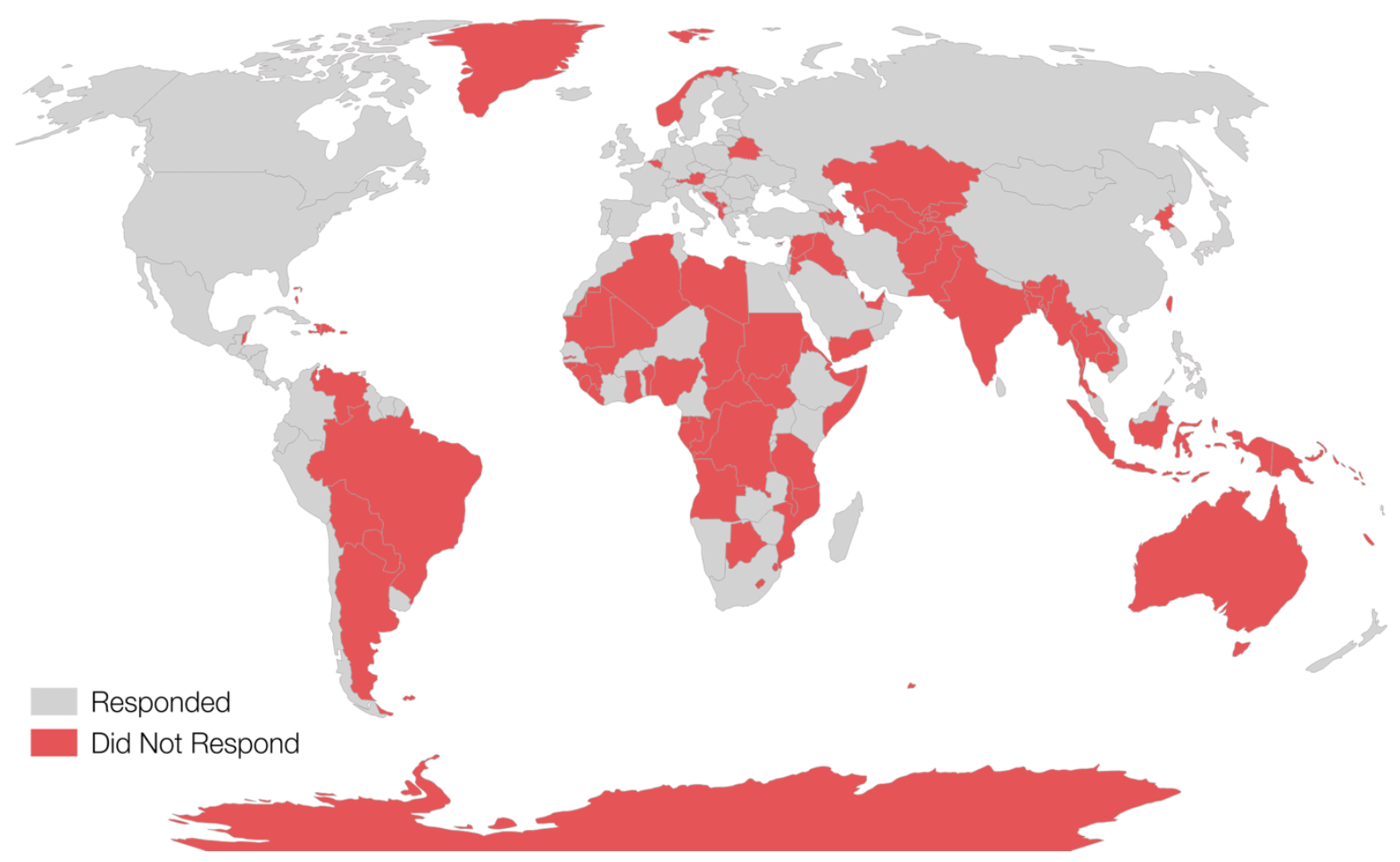

Figure 1: Countries that did not respond to the survey published by Konecny et al. (2016). Background data from Natural Earth (https://www.naturalearthdata.com). In colour online.

Other methodologies deployed in more nuanced, detailed and narrative accounts confirm the politics that underpin and limit progress and are grounded in the appreciation that mapping inevitably reflects society. Mapping requires resources to compile and produce, and as such, all else being equal, richer areas or nation states are likely able to create and maintain a greater diversity of more current mapping, compiled and maintained to greater accuracy, and delivered through professionally staffed institutions (Parry and Perkins, 2000). There are also likely to be significant variations within nations that are hidden in aggregated national values, whereby urban areas are best mapped, and rural areas have the most out-of-date coverage and the least detailed mapping (Haklay, 2010), particularly in the Global South (Chen et al., 2019). Mapping also takes time to develop and as such the history of cartography continues to influence contemporary provision. Colonial mapping specifications are likely to continue to impact on contemporary practice, even half a century after the end of empire (Akerman, 2017) and technological changes offering apparently global solutions in practice are also strongly influenced by local factors. The widespread diffusion of Google Maps and similar products on smartphones, for example, offers an apparently comprehensive global coverage, but access to 
smartphones and mobile infrastructure varies greatly (Chinn \& Fairlie 2007), and the content and quality of the maps themselves varies substantially from place to place.

Simple indices of topographic coverage have additional flaws beyond their methodological practice, such as a failure to chart the full diversity of mapping. Parry and Perkins (2000) highlight the fact that many different agencies are involved in mapping in addition to national mapping agencies, and that mapping has historically been published in genres of which topographic mapping has probably been most significant. Coverage will vary for each, but once again the rural global south is likely to be worst mapped. Technological change has also frequently disassembled the previously unified topographic map with data themes identified to encourage standardised practice for the dissemination of data through SDI (Scott and Rajabifard, 2017). Once again coverage is likely to vary, with digital mapping of the global south being less frequent, less available and less fit for purpose than in richer societies.

A further issue with coverage as a metric lies with the availability of maps. The existence of a map does not necessarily mean that it is accessible, either because authoritative national mapping is regarded as a political device and may be restricted, because maps are too expensive for many members of the population, or simply because there are not sufficient outlets at which maps may be acquired. In Russia, China and most parts of Asia and the Middle East, for example, states limit who can acquire mapping, and even available maps are likely to leave some sites off their publicly published coverage when these are deemed sensitive (such as military bases or critical national infrastructure) (see Perkins and Dodge, 2009). A final problem with coverage stems from the limited way in which such indices deal with temporality. Even in Western Europe and North America many national government mapping agencies have neither the funding nor the mandate to keep their mapping databases current within specified time frames. Public budgets for topographic mapping are declining or non-existent in many jurisdictions in the Global South (Coleman et al., 2009) and as a consequence, mapping from the colonial era may be the only available topographic coverage in many regions. 
So despite the optimistic trends in overall coverage charted in the 'Status of World Mapping' database, maps of countries in the Global South are often inferior in coverage, quality and availability, and frequently well beyond the limits of their useful life. In practice, global coverage of 'authoritative' topographic mapping is probably growing far more slowly than is estimated, and could even be reducing in some regions. It is notable that the UN-GGIM 'five to ten year vision' frames the use of geospatial information towards the achievement of the UN SDGs, but makes no attempt to address the lack of mapping coverage in the Global South. Instead, it favours topics such as data standards, or data interoperability (Norris, 2015). It does, however, acknowledge that "many of the critical issues where geospatial information can assist are found in developing nations" (Norris, 2015: 31), and also refers to the lack of high-quality mapping in Africa specifically, stating that "the lack of consistent up-to-date base mapping ... across Africa remains a challenge" (Norris, 2015: 7). Nevertheless, no solutions or action plans are posited in the document. It is for this reason that VGI has grown in popularity in areas for which up-to-date mapping is not otherwise available. The following section will describe the development and academic context of VGI, before providing an overview of the challenges that are limiting the growth of VGI mapping coverage in many of the under-mapped parts of the world.

\section{Volunteered Geographical Information}

Despite a growing body of research into VGI in the past decade, its definition remains somewhat nebulous, encompassing a wide variety of data types and modes of volunteering (Craglia et al., 2012), and an even wider range of activities, practices and motivations (Haklay, 2013). A number of typologies of VGI have been developed, the most frequently cited of which focuses upon the distinction between explicit or implicit 'volunteering' and 'geographic information' (Craglia et al., 2012). Here, we refer only to VGI that may be considered as both 'explicitly volunteered' and 'explicitly geographical', the archetypical example of which is the user-generated content of OpenStreetMap (OSM). OSM was originally intended as a response to the strict licensing associated with national mapping agencies such as the Ordnance Survey and the then emergent web mapping 
services (such as Google Maps), but has increasingly come to be used in humanitarian mapping over the past decade (Anderson et al., 2019).

Traditional research agendas for VGI have emphasised the data and individual contributors, with early publications discussing the implications of VGI for science (e.g. Gartner et al., 2007; Goodchild, 2007) and society (e.g. Obermeyer, 2007) and the motivations of individuals to participate (e.g. Coleman et al., 2009). More recent research, however, has sought to advance understanding of the concept of VGI by viewing it as a complex social practice, rather than merely data production (Haworth, 2018). In this context, VGI has implications for society and geography far beyond the opportunities presented by a network of individual observers or distributed data contributors (Haworth, 2018). Nevertheless, two research themes have predominated: the first of which lies in the application of VGI in the management of disasters (e.g. Crutcher and Zook, 2009; Zook et al. 2010; Haworth and Bruce, 2015; Granell and Ostermann, 2016; Haworth, 2016; Haworth, 2018). OSM and other VGI platforms have been increasingly utilised in the past decade to support humanitarian and disaster relief efforts, providing emergency responders with information about where those in the greatest need are located and how to deliver assistance (Zook et al., 2010). Given the immediate need for reliable maps in humanitarian and disaster scenarios, peer-produced mapping allows a greater number of maps to be produced in a shorter period of time, permitting scarce resources (e.g. volunteers located in-country) to be diverted to tasks that cannot as easily be undertaken by distributed networks of remote volunteers (Zook et al., 2010). Prominent examples of the use of VGI in disaster relief include the use of Google Earth in the response to Hurricane Katrina in the USA in 2005 (Crutcher and Zook, 2009), and the use of OpenStreetMap in response to the magnitude 7.0 earthquake that struck Haiti (2010), Typhoon Yolanda (2013), the Ebola Crisis (2014) and the Nepal earthquake (2015) (Zook et al., 2010; Anderson et al., 2019).

The second theme concerns the evaluation of VGI data quality (e.g. Elwood, 2008; Flanagin and Metzger, 2008; Haklay et al., 2010; Zielstra and Zipf, 2010; Goodchild and Li, 2012; Senaratne et al., 2017), typically by comparison with existing 'authoritative' datasets. Research has framed data quality as "a crucial question about the efficacy of VGI activities and the value of outputs for a range 
of applications" (Haklay et al., 2010: 315) and as a "key concern" for VGI to emergency management (Haworth, 2016: 194). It is interesting that, even though VGI had already become an important source of maps for a variety of humanitarian purposes (Haworth and Bruce, 2015), Sui et al. (2013:6) suggest that "information is usually the least available where it is most needed". In recent years in the Darfur crisis in Northern Sudan (2006), the aftermath of the Haiti earthquake (2010) and the BP 'Deepwater Horizon' explosion in the Gulf of Mexico (2010), for example, no detailed mapping was available to support relief efforts (Sui et al., 2013). Indeed, more obscure, remote, and unknown features are less likely to be mapped in OSM, except perhaps when a disaster generates prominence in international media, creating an impetus for voluntary mapping. This is an important issue, because the vast majority of un-mapped areas can typically be expected to be remote and rural areas, typically with sparse populations and little or no access to the Internet. Haiti, for example, as one of the world's poorest countries, had simply not created demand for mapping, resulting in a lack of 'adequate coverage' in standard mapping platforms (Zook et al., 2010). This issue is compounded, as a lack of initial data prevents further mapping through the effect of map seeding, in which data coverage and quality are more likely to improve in areas where some data already exists (Anderson et al., 2019).

The result of this is that VGI exhibits similar patterns of inequality in mapping coverage as those already identified in 'authoritative' sources of mapping. Studies of the spatial distribution of VGI posted by Google Maps users, for example, demonstrate inequality at global and local scales, comprising an overrepresentation of higher income places and popular tourist destinations, and an under-representation of lower income places (Crutcher and Zook, 2009; Elwood, 2010; Zook et al., 2010). Similarly, Graham and Zook (2011) identified that Louisville, Kentucky had fifty per cent more content in OSM than the entire country of Iraq, and that the Tokyo metropolitan region had three times as much content as the entire content of Africa. Even around London (UK), Haklay et al. (2010) found that rural areas had larger positional errors than in more urban locations.

The digital divide reinforces these patterns of inequality in mapping coverage. (Chinn and Fairlie, 2007; Hagenauer and Helbich, 2012). This inequality in access to digital services stems from different levels of access to electricity, computing equipment, mobile devices and Internet connections, as well 
as the necessary time and skills to use them effectively (Haworth, 2016). The 'digital divide' has been identified as a major limitation to the uptake of VGI (Haworth, 2018), and inequalities in VGI coverage across the surface of the Earth mirror the inequalities charted above in the case of authoritative topographic mapping. OSM, for example, has acquired a "strikingly comprehensive" dataset on large parts of the developed world, although other parts of the world (predominantly those in the Global South) are underrepresented (Elwood et al., 2012: 576). The exclusion and underrepresentation of information from and about people and places can result in the exclusion of their needs and priorities from policy and decision-making, resource allocation and service provision (Elwood, 2008). It is also important to consider the converse of exclusion: people and parts of the world that can participate, gaining increased benefits and potentially widening existing divides (Haworth, 2018).

These research concerns about inequalities in data access are interesting because, since the emergence of web mapping around 2005, researchers have increasingly considered VGI as a viable alternative to the 'authoritative' maps produced by national mapping agencies. Nevertheless, Konecny et al. (2016: 34) only acknowledged it with a single bullet point stating that, whilst it had been "enthusiastically promoted" in most parts of the world, "it must be integrated into authoritative mapping to guarantee quality control". In fact, even national mapping agencies in the Global North, who are best placed to incorporate VGI into their authoritative production systems, have so far largely failed to exploit the opportunity (Coleman, 2013). This is in part because of employment fears from staff, legal issues relating to crowdsourced data and its ownership, and the long-term sustainability of the data source (Oltenau-Raimond et al., 2017). This lack of uptake also reflects concerns over data quality, and stems from social issues related to volunteer motivation and pragmatic configurations of technology in practice. It is to these issues that we now turn.

\section{Motivations for VGI Contributors}

A primary challenge for addressing mapping inequalities is that maps have always only been published for themes and places where demand justifies production costs (Elwood et al., 2012). Whilst VGI reduces costs in comparison to traditional practices for national mapping agencies, costs 
are not completely removed. In addition to the time and equipment cost for volunteers (e.g. computer, internet connection GPS receiver, mobile phone or printer), organisations require substantial resources to be able to utilise VGI effectively, with data management being one of the key challenges (Haworth, 2016). The existence of well supported, high capacity platforms such as OSM and the flourishing set of open source software projects surrounding it mean that VGI approaches to mapping can be deployed more easily than ever before. Nevertheless, VGI mapping remains limited to the locations and features that volunteers want to map.

It is therefore important to understand what motivates people to contribute data to VGI platforms such as OSM (Flanagin and Metzger, 2008, Goodchild and Li, 2012). Coleman et al. (2009) propose a list of eight potential motivations: altruism, interest, intellectual stimulation, protection or enhancement of a personal investment, social reward, enhanced personal reputation, self-expression and pride of place (where place refers to the location being mapped). Zook et al. (2010) propose a simpler list: the desire to gain social capital, the desire to gain technical knowledge and the desire to gain a rewarding educational experience; as well as the inaccessibility and cost of alternative sources of data and simply the desire to 'fill in the blank spaces' on the map (see also Goodchild, 2007; Sui et al., 2013). In either case, these motivations could be conflated as either egocentric or allocentric: driven by personal benefits, or by more altruistic factors, respectively. There has been little research into the relative influence of these different motivations, but the patterns in quality and completeness described above (c.f. Haklay et al., 2010; Zielstra and Zipf, 2010), indicate that people largely only map places that they care about in an egocentric fashion, such as their own neighbourhood or a favoured holiday destination; or those that are identified by some emotive and allocentric influence, such as mapping in response to a disaster as part of relief efforts. It follows, therefore, that it is unlikely that volunteers will be as easily motivated to undertake extensive mapping of remote and unknown regions that are not experiencing well publicised acute humanitarian crises. We suggest that a solution to generating map coverage for such regions might then lie in the development of technical approaches to VGI that are more appropriate for rural and remote regions, focusing upon the 
egocentric motivations such as intellectual stimulation or desire to gain technical knowledge, rather than simply attempting to motivate existing mappers to shift attention to such regions.

Much of the VGI coverage in remote and rural parts of the Global South relates to mapping in support of organised responses to acute humanitarian crises in very specific locations; leading to the production of high quality mapping over quite small and normally urban areas to support a particular purpose, such as the mapping of the world's largest slum: Kibera in Nairobi (Hagen, 2010). Organisations such as the Humanitarian OpenStreetMap Team and Missing Maps are undoubtedly improving map data for disaster response and preparedness, but remote and sparsely populated regions experiencing longer-term 'chronic' issues are unlikely to become priorities in their task lists, and lack the emotive drivers necessary to mobilise large numbers of volunteers. Furthermore, the workflow for some such organisations is often designed to focus on specific crises (e.g. a disease outbreak), and can be spatially limited, meaning that 'complete' regional mapping is unlikely to be achieved through such efforts. For example, the Humanitarian OpenStreetMap Team mapped the town of Lira in Uganda in great detail in 2014 as a preparatory measure in case of future humanitarian need. Even at the time of writing (five years later), the bounding box around their project is clearly visible on the map, demonstrating an almost total lack of further mapping activity in the area (Figure 2). Whilst the addition of this information to the map is beneficial, the contrast between the urban detail and the surrounding rural areas serves to highlight one of the chief difficulties associated with volunteer mapping at the regional or national scale: whilst local scale mapping can often be achieved with great levels of success, deploying the same techniques over a larger area remains a challenge.

This challenge can be addressed either through increasing levels of motivation (and by extension the number of 'volunteer hours' available for mapping), or by improving the efficiency and efficacy of existing volunteers through technological means, so that more mapping can be achieved per 'volunteer hour', without a reduction in quality. We suggest that the latter might be achieved by adopting centaur approaches to VGI production. 


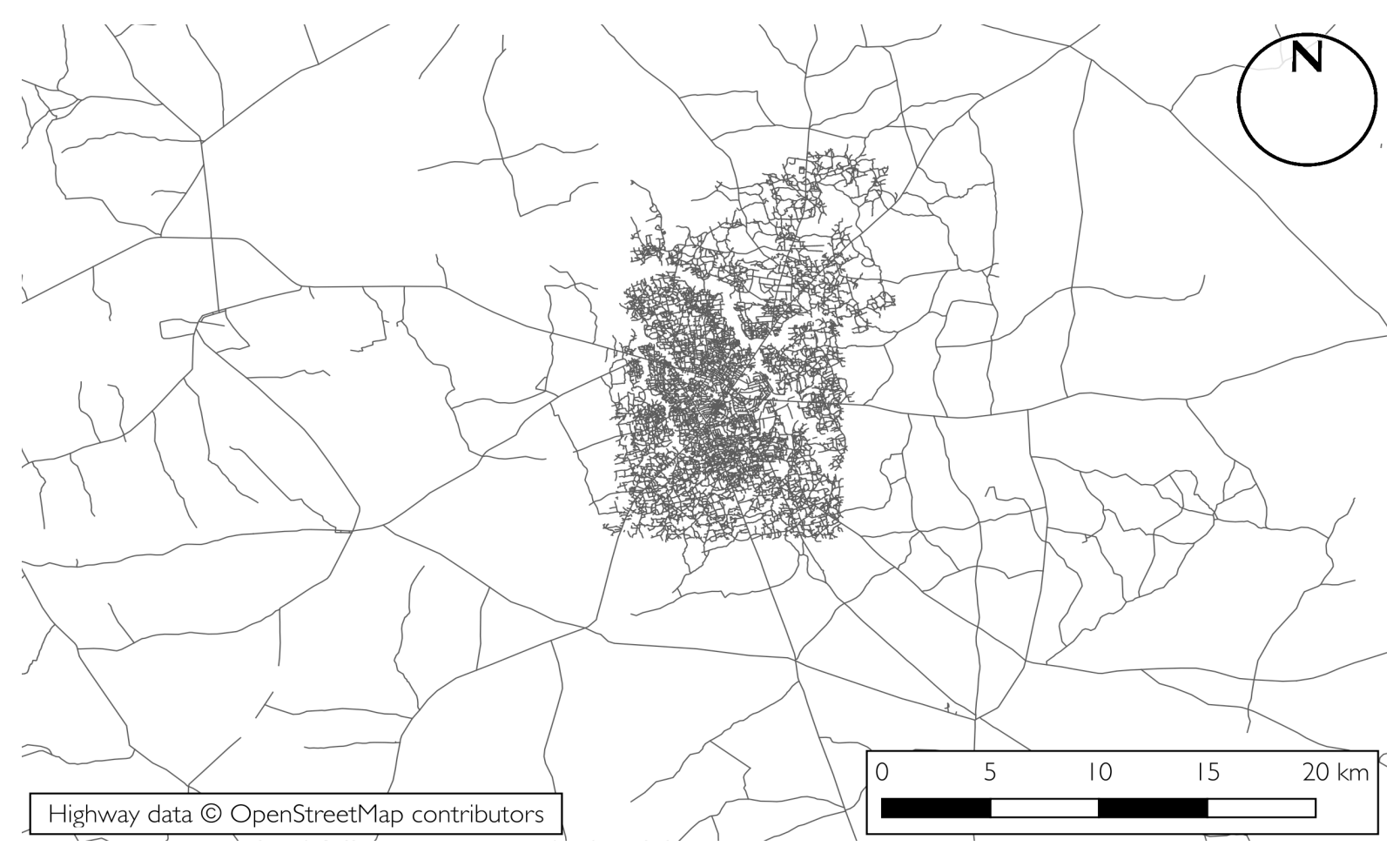

Figure 2. OpenStreetMap 'highway' (road and footpath) data around the town of Lira, North Uganda. The square outline of the digitisation exercise can clearly be seen. Highway data (C) 2019 OpenStreetMap contributors.

\section{Integrating VGI and Machine Learning}

Though VGI provides an invaluable resource for many humanitarian applications, further consideration needs to be given to how it might address persistent inequalities in global mapping coverage. ML has been one of the most successful areas of computer science research in recent decades, with applications in a wide variety of fields (Gillies et al., 2016). Though it remains difficult for non-experts to use (Gillies et al., 2016), the emergence of increasingly high-level ML platforms such as Google TensorFlow is rapidly lowering barriers to entry, resulting in the application of ML techniques to a wide variety of problems in almost all fields of research (Jordan and Mitchell, 2015). From a mapping perspective, one of the clearest applications of ML techniques is feature recognition in remotely sensed imagery. A typical system is conceptually relatively straightforward:

1. A 'training set' of data is created in which features such as roads, footpaths or buildings in imagery data are manually identified and 'labelled' 
2. The 'training set' is used to 'train' an algorithm, which 'learns' how to recognise the labelled features using statistical analysis

3. The 'trained' algorithm is then used to search for the same statistical patterns in new imagery and identify new features

A comprehensive review of the literature relating to the classification of images for mapping is beyond the scope of this article, and can be found elsewhere (e.g. Zhu et al., 2017). Rather, we argue here for the integration of ML with human activities, as against replacement of the human activities with the machine, which has been a more traditional goal in ML research.

It is widely acknowledged that OSM constitutes an extremely valuable yet relatively underexploited source of training data for geographical applications in ML (Herfort and Zipf, 2018; Chen and Zipf, 2017). The automated detection of features such as buildings, roads or settlements in satellite imagery using ML approaches and VGI training data has been addressed several times in the literature (e.g. Hagenauer and Helbich, 2012; Herfort and Zipf, 2018; Li et al., 2019; Herfort et al., 2019), including in rural African settings (e.g. Chen and Zipf, 2017; Chen et al., 2019). Attempts have also been made to integrate ML into OSM workflows, for example by presenting a comparison of the number of buildings in the OSM database at a given location with estimated 'on the ground' building counts generated using ML feature detection (e.g. OSM Analytics, 2019; Disaster Ninja, 2019). Such tools are highly useful for directing volunteers towards locations that require mapping, and also reiterate the lack of mapping data available in many parts of the Global South, but little work has been carried out into how ML might be used to directly enhance crowdsourced datasets (Herfort and Zipf, 2018). A move in this direction has recently been made by Facebook's mapwith.ai platform (Map with AI, 2019), though this is focused upon acute humanitarian response and currently is therefore only currently available in a limited number of countries. Nevertheless, investment such as this by large commercial organisations such as Facebook, alongside other major investments in the improvement of international map coverage by organisations such as Amazon, Apple and Microsoft (Anderson, 2019) serves to illustrate the value of these maps both from a humanitarian and commercial perspective. 
In spite of a rapid growth in academic literature attempting to link OSM and ML in recent years (Yuan et al., 2018; Chen et al., 2019; Herfort et al., 2019; Li et al., 2019; Vargas-Muñoz et al., 2019) it is notable that almost all of this reported research focuses on the evaluation of different approaches (in terms of accuracy, precision or other quality metrics) rather than devising practical systems for delivering data. Notably, none of them report an upload of resulting datasets into OSM, which is likely to be due at least in part to the fact that bulk importing into OSM is carefully regulated by the community (OpenStreetMap, 2019a) and that gaining approval for such imports can be challenging (Anderson et al., 2019). OSM community attitudes towards bulk imports and 'automated edits' can be negative and cautious (OpenStreetMap, 2019a; 2019b; 2019c), with vocal minorities in the OSM community appearing to strongly oppose the use of such approaches. Though there certainly have been many instances of successful data uploads over the duration of the project (Anderson et al., 2019), OSM also maintains an online list of data imports that have been or will be deleted (OpenStreetMap, 2019d), and the threat exists that imports of data might be deleted and user accounts blocked if the upload falls foul of OSM community guidelines (OpenStreetMap, 2019a). Increasing interest in the use of ML amongst some of key organisations affiliated with the OSM community (e.g. Smith, 2018; Herfort et al., 2019) may lead to increased uptake, but balancing the requirement for high quality data, some community members' views for how OSM data should be collected, and the realities of ML means that it is unlikely that we will see a significant uptake in wholly machinegenerated map features in the near future. Rather, it is expected that these technologies will continue to be applied to quality control, and focus on the improvement of data within existing OSM coverage, or identifying areas that require manual mapping by volunteers.

However, there is room for alternative, complementary approaches to integrating ML into OSM digitisation workflows. In the next section, we propose such an alternative by elaborating on the idea of centaur VGI, and show how such an approach can help the benefits of ML to be realised, without the need to replace volunteers or the standard OSM editors and workflow, but ensuring that mapping efficiency is increased whilst still meeting the expectations of the OSM community.

\section{Centaur VGI}


The apparent tension between the desire of computer scientists to automatically detect features and the resistance of the OSM community to accept automated edits reveals a possible middle ground: a centaur VGI approach, whereby the classification accuracy and common sense of manual human input can be combined with the speed of the machine to enable more efficient volunteer mapping, whilst also delivering a system that is compatible with the ethos of OSM. This centaur VGI workflow is summarised as:

1. Computer searches satellite imagery for previously un-mapped feature

2. Computer proposes geometry for feature

a. Volunteer approves, edits or rejects geometry

b. Computer incorporates edits and rejections into the training set to improve performance

3. Computer proposes classification for feature

a. Volunteer approves or edits classification

b. Computer incorporates edits into the training set to improve performance

4. Volunteer submits edits to OpenStreetMap

This kind of centaur-based approach can integrate seamlessly into existing editors such as the OSM iD editor (OpenStreetMap, 2019e) or JOSM (2019) software. It removes the need for users to search for features, by providing in-editor suggestions that can be accepted, modified, or rejected before submission to the OSM database. Edits and rejections are fed back to the training set to improve the performance of the classification algorithm. Such an approach permits the human volunteer to concentrate on the classification and verification of the data, whilst more onerous, frustrating and time-consuming tasks such as searching for features across sparsely populated rural areas and tracing around the edges of features can be machine-based, resulting in a more productive experience for volunteers and increasing potential for greater volumes of data to be collected per 'volunteer hour'. Crucially, whilst the machine proposes a geometry for each feature, it is the human volunteer who accepts, edits or rejects it. This is important as, though ML techniques show promising results in 
feature detection, analysing and ensuring the quality of the resulting data remains a "huge challenge" (Herfort et al., 2019: 3).

Centaur VGI is akin to approaches identified in the literature as "interactive Machine Learning" (iML) or 'human-in-the-loop', where human domain experts are considered indispensable elements in the data processing pipeline (Holzinger, 2016). Such approaches are well suited to VGI, as they are intended for situations when human operators are able to undertake a task with great reliability, but without being able to explain their rules explicitly (Holzinger, 2016). Centaur VGI may therefore be considered as a more human-focussed version of iML in which people remain in control of every single feature that is digitised, being aided or augmented rather than replaced by the machine. This dual approach fulfils the requirements of the OSM community and maintains quality, whilst also increasing speed and efficiency of volunteers working in remote unmapped parts of the world. Centaur approaches have been deployed in fields as disparate as professional chess, stock market trading, warfare, medical imaging and baseball scouting (Holzinger, 2016; Domingues, 2017). There is clear potential for such approaches to be applied to the rural, unmapped regions of the Global South, and for those maps to be used for a wide variety of humanitarian, medical, infrastructure, and service applications.

Centaur approaches to mapping could also potentially contribute to Active Learning and further improve the performance of the human-computer team. Active Learning (AL) is a variant of ML in which the machine is able to select features for digitisation that can be incorporated into the training set. In this scenario, the volunteer takes on the role of the oracle (in the ML parlance, c.f. Settles, 2009; Holzinger, 2016; Bernard et al., 2018) as well as the mapper; generating map data whilst simultaneously providing optimised training material to the machine to increase the quality of future suggestions that it will make. AL is intended to minimise the required size of training sets by allowing the machine to ask questions, just as a human learner would (Yang et al., 2018). AL approaches have been deployed with great success in the literature, and to many different areas of application, (Yang et al., 2018), and are already being used to aid feature classification in remote sensing (Patra and Bruzzone, 2011; Stumpf et al., 2014; Liu et al., 2017; Yang et al., 2018). 
The literature identifies a wide variety of different approaches to the selection of features for AL that the classification algorithm finds difficult to classify with low levels of uncertainty. Asking a human to classify such a feature and incorporating the result into the training set teaches the algorithm what to do in such a case, and therefore improves the classification of subsequent features. Uncertainty in a training set typically arises when there is conflicting evidence about the class to which a feature should belong (conflicting evidence uncertainty), or when there is insufficient evidence to be sure about the class a feature should belong to (insufficient evidence uncertainty) (Sharma and Bilgic, 2017). AL techniques have been shown to be beneficial for both forms of uncertainty, but particularly for the former (Sharma and Bilgic, 2017). There are various approaches to the selection of the best features to query in AL, but common approaches may be summarised as: query by committee, where multiple classifiers are used to classify an image and the samples with the greatest level of disagreement are selected; max-margin sampling, where samples with the greatest levels of uncertainty in the classification algorithm are selected, and; max-entropy sampling: where probabilistic modelling is used to determine values for uncertainty, and those with the highest values are selected (Du et al., 2017).

AL approaches also have additional advantages when applied to VGI (and OSM in particular). They aid human understanding of how the algorithm works; volunteer mappers are better able to understand how the machine works because of the interaction with it (Holzinger, 2016; Gillies et al., 2016; Yang et al., 2018) and even contribute in an overt and meaningful way to its success, rather than merely relying on the machine to do the work. For volunteers, these benefits can constitute egocentric motivations for participation, which could be more powerful than allocentric motivations in the case of regions with few points of interest and little media presence, thus increasing the likelihood that such a location might be mapped. With respect to the OSM community, the volunteer remains the primary actor for mapping, which might make the approach more acceptable to those parts of the community who are less content for ML techniques to be incorporated into feature digitisation. We conclude by showing how such a system might be realised in the context of our work in Acholi, Uganda. 


\section{Research Context: Mapping Acholi, Uganda}

Whilst the arguments we present in this paper are framed in the context of global topographic mapping, they have primarily been formulated in the context of the authors' on-going research and humanitarian activity in the Acholi sub-region of northern Uganda (Figure 3). This area was the focal point of a brutal conflict arising from an insurgency by Joseph Kony's 'Lord's Resistance Army' (LRA), which lasted for almost two decades during which atrocities were committed on a regular basis including the kidnapping and enslavement of young children, severe mutilation, and the internal displacement of 90 per cent of the population (Vinci, 2005). The period between 1986-2005 is generally accepted as the duration of the conflict (Lamwaka, 2016), but its legacy, including injuries from landmines placed in villages and fields, continues to this day. Acts of mutilation from the LRA contributed to the prevalence of disabilities in the region and were intended to be highly visible and symbolic. Mutilation was used to control the population (Vinci, 2005): ears and lips, for example, were cut off as a signal to beware of informing on the LRA, whereas bicycle riders had their legs cut off inhibit communication amongst the local population (Vinci, 2005). Our research primarily comprised undertaking the first ever prevalence study of disability in the region with a particular focus on major limb loss, followed by the design and implementation of an orthopaedic outreach service to provide prosthetic limbs and associated care for victims in the region (Okello et al., 2019). Needless to say, it is impossible to either conduct a robust prevalence study or to implement comprehensive orthopaedic outreach clinics without access to large-scale current maps of the Acholi sub-region. 
A

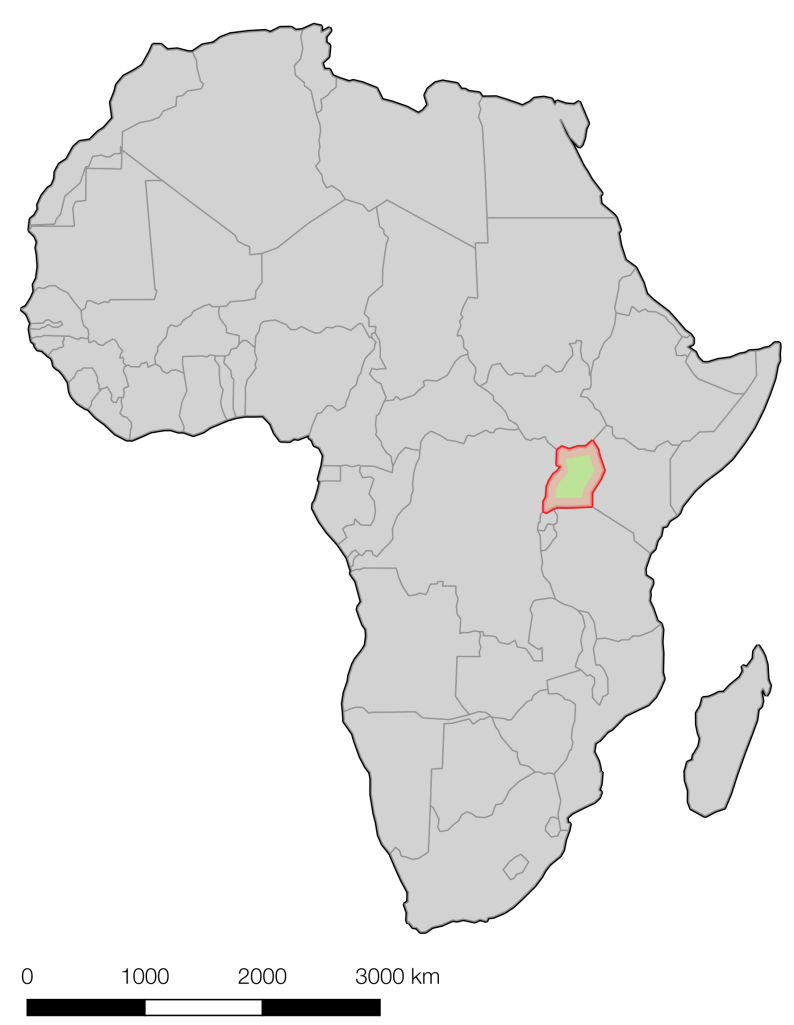

B

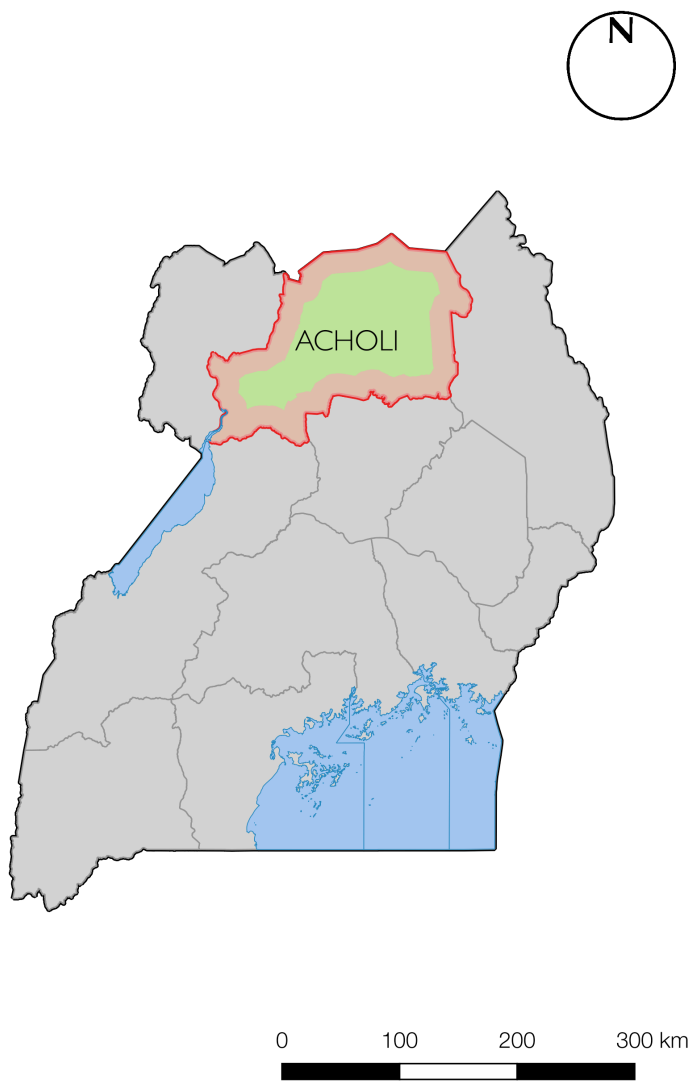

Figure 3. Maps displaying (A) the location of Uganda in Africa; and (B) the location of the Acholi Sub-Region in Uganda.

Uganda did respond to the 'Status of World Mapping' questionnaire and was classified accordingly as being mapped with $100 \%$ coverage at the $1: 50,000$ scale (Konecny et al., 2016). Whilst there is a complete series of maps of Uganda produced at the 1:50,000 scale (see Figure 4), an examination of the map sheets themselves reveals that they were released between 1958 and 1969 by the British Directorate of Overseas Surveys (formerly Directorate of Colonial Surveys), whose remit was to provide a central survey and mapping organisation for British colonies and protectorates, and that they were based upon aerial imagery and field surveys collected between 1948 and 1961, whilst Uganda was still a British colony. Responsibility for the production of these maps currently lies with the

\footnotetext{
${ }^{4}$ A complete set of the maps are available in the Map Collection at the University of Manchester. A digital 'slippy map' version covering the Acholi sub-region is available at http://huckg.is/uganda50k
} 
Uganda Surveys and Mapping Department in the Ministry of Lands Housing and Urban Development. In common with other national mapping agencies in the east African region, only limited progress has been made in updating topographic mapping coverage, which remains analogue in form (Baariu et al., 2019). Though Japanese and French aid has enabled some of the sheets to be updated using SPOT satellite imagery in 1998, 2003 and 2007, this activity has been limited in scope, with only 104 of the 317 sheet series revised, (32.8\% of the series), almost all of which are around the capital city of Kampala in South Uganda and in the West Nile region in the North-West. Only a single sheet has been updated in the Acholi sub-region (Sheet 15/1 Palabek, 2007), and upon inspection the update appears limited, comprising only the addition of two small areas of woodland.

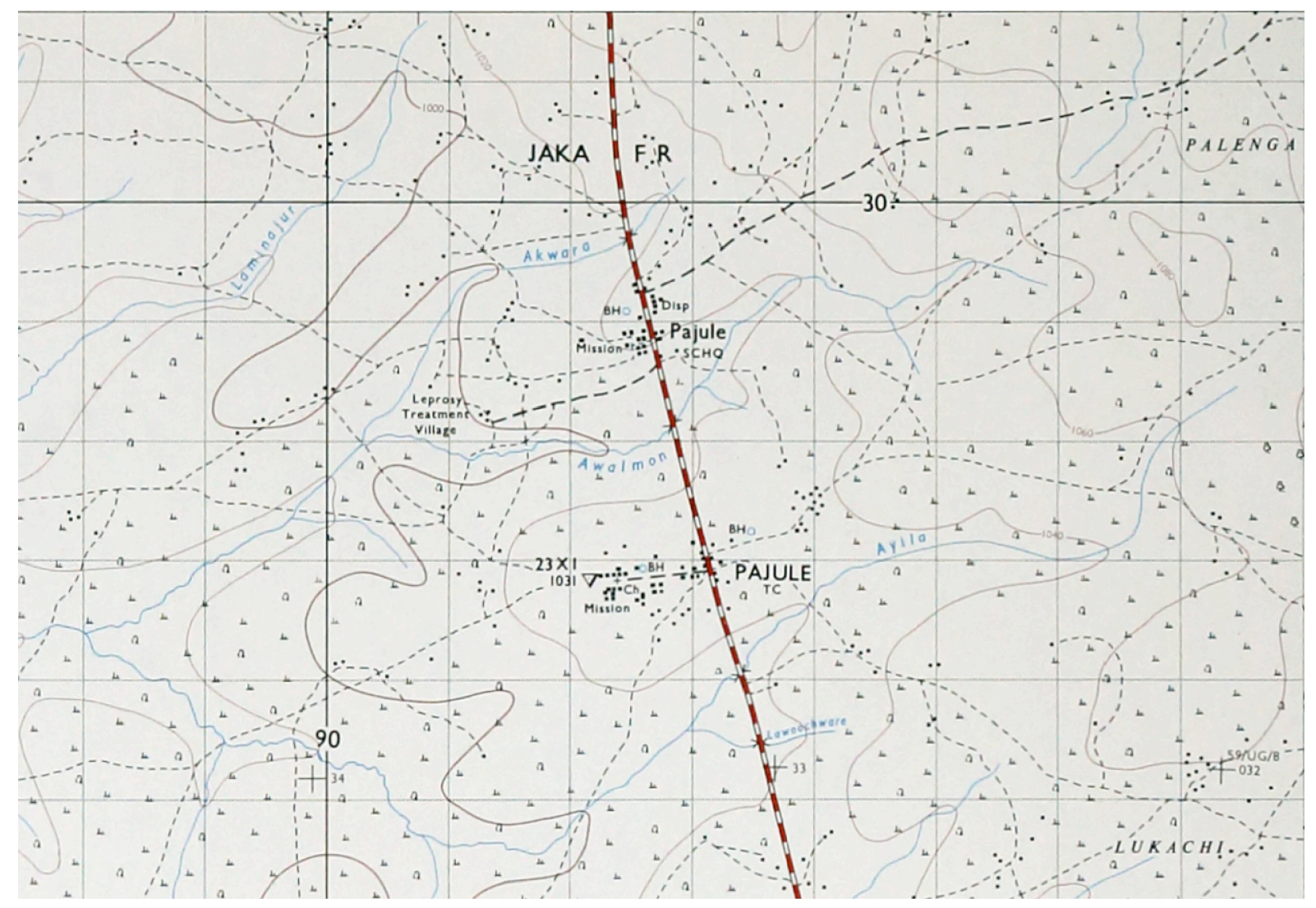

Figure 4. Excerpt of sheet 23/2 (Pajule) of the Directorate of Overseas Surveys 1:50,000 map of Northern Uganda, published 1968. In colour online.

Topographic maps of the majority of Uganda are therefore long out-of-date, a condition that is exacerbated in the Acholi sub-region by nearly wholesale displacement of the population during the conflict, exponential population growth and the impermanent nature of buildings and infrastructure, 
largely comprising un-surfaced roads and clay huts with thatched roofs. As a result, these maps are only useful today for locating major routes and population centres that they connect. Accordingly, it is reasonable to argue that these maps are no longer 'authoritative', and that Uganda should no longer be classed as having $100 \%$ map coverage at this scale by the UN-GGIM 'Status of World Mapping' report.

The lack of current maps of Acholi made the production of a rigorous sampling strategy impossible and the design of a comprehensive outreach model for the orthopaedic clinic extremely challenging. The twenty-year conflict had received little international media coverage, occurred prior to the widespread uptake of VGI amongst humanitarian agencies and the region is predominantly very rural with few points of interest, so the vast majority of northern Uganda was poorly mapped in VGI databases such as OpenStreetMap (OSM). For these reasons, we began a VGI mapping campaign using OSM, which engages schools, youth groups, students, private companies and members of the public in order to generate map data for the region. In accordance with standard OSM practice, mapping activities are also led by volunteers in-country as much as is possible, with data produced as part of this project being 'ground truthed' and improved through the addition of additional features and attributes by a team of volunteers based at Gulu University, using Portable OpenStreetMap systems (POSM, 2019).

The design of the project meant that we are not able to precisely quantify our contribution to the OSM database, though an inspection of OSM contributions in the region since we began in July 2017 clearly illustrates a substantial increase in coverage during this period (Figure 5). This increase includes the activities of our project, as well as some independent mapping activity from other groups and individuals and ten projects organised by the Humanitarian OpenStreetMap Team mapping large refugee camps in the region. Nevertheless, according to OSM Analytics (2019), at the time of writing, known usernames used exclusively for the project account for $24 \%$ of building mapping and $53 \%$ of road mapping in the Acholi sub-region. 


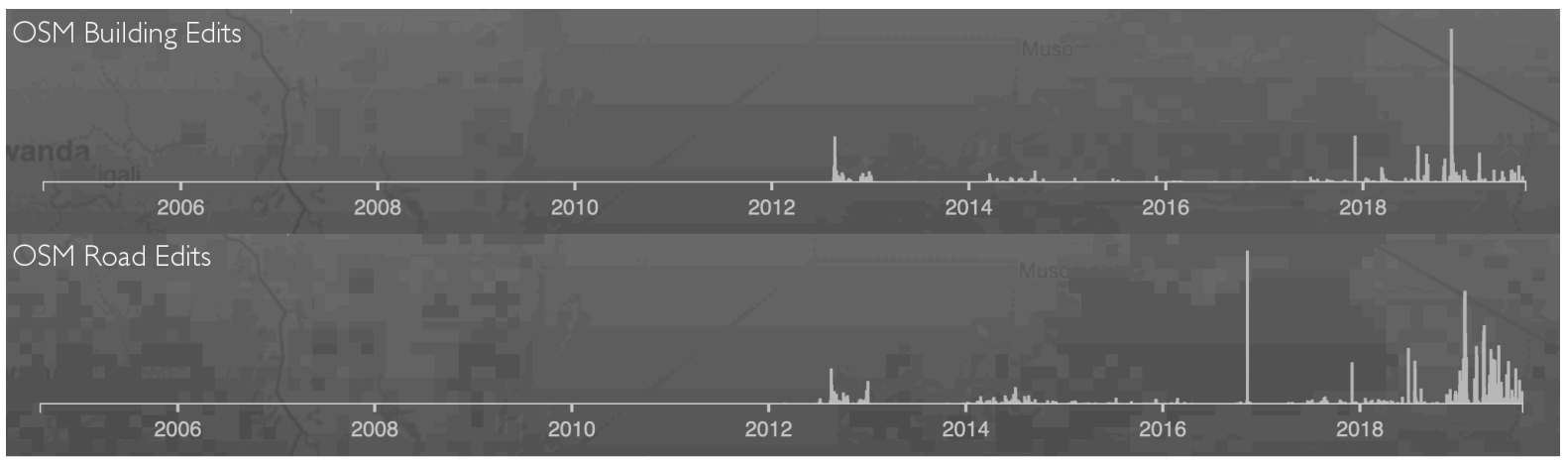

Figure 5: OSM Mapping Activity (buildings above, roads below) in the Acholi Sub-Region. Taken from OSM Analytics (2019).

The workflow for the project is similar to that of other VGI mapping organisations, such as the Humanitarian OpenStreetMap Team, and is illustrated in Figure 6. From the perspective of a volunteer mapper, the process is managed by a bespoke website (Figure 7; Huckathon, 2019) that provides volunteers with areas of interest based upon project priorities (which, in turn are primarily dictated by the needs of the clinic operation). This is analogous to Task Managers used to manage digitisation projects by the Humanitarian OpenStreetMap Team (HOT, 2019), but focuses on a much larger area than these projects. Once assigned an area by the task manager, volunteers are asked to compare high-resolution satellite imagery against the OSM map and indicate whether there are currently features missing. If so, the volunteer can choose to start mapping, at which point they are directed to the OSM iD editor (Figure 6, Step 1). Volunteer edits are uploaded to OSM and flagged in the task manager to be validated by an experienced member of the Team (Figure 6, Step 2). Following this, data are periodically uploaded to POSM servers, which are transported to Gulu University in the Acholi sub-region. A team of trained volunteers then use the POSM to produce paper maps of the areas, which are taken into the field and manually edited with a pencil, before being uploaded and digitised. Local mappers use this opportunity to validate features and add additional information such as place names, road names, and building uses; as well as features that cannot easily be mapped using satellite imagery, such as boreholes (Figure 6, Step 3). The POSM is then returned to the project team in the UK, who upload edits to OSM using the POSM Replay software and produce updated paper 
and digital maps for use by researchers and the staff of the mobile orthopaedic clinic (Figure 6, Step 4).

\section{Typical Map Production Workflow}

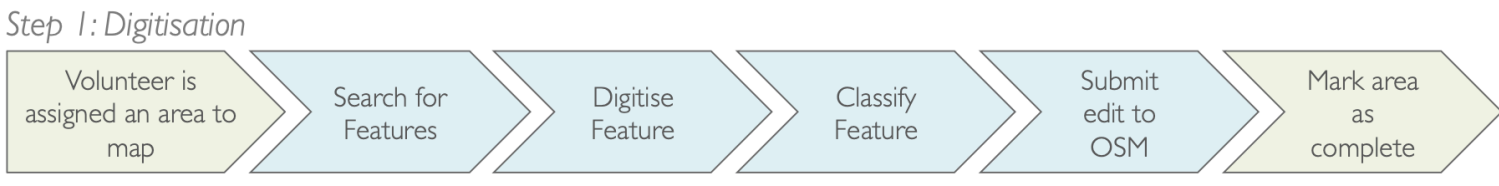

$\left.\left.\left.\left.\begin{array}{l}\text { Step 2: Remote Validation } \\ \left.\begin{array}{c}\text { Volunteer is } \\ \text { assigned an area to } \\ \text { validate }\end{array}\right\rangle \text { validate } \\ \text { feature } \\ \text { geometry }\end{array}\right\rangle>\begin{array}{l}\text { Validate } \\ \text { feature } \\ \text { class }\end{array}\right\rangle\right) \begin{array}{l}\text { Submit } \\ \text { edit to } \\ \text { OSM }\end{array}\right\rangle$

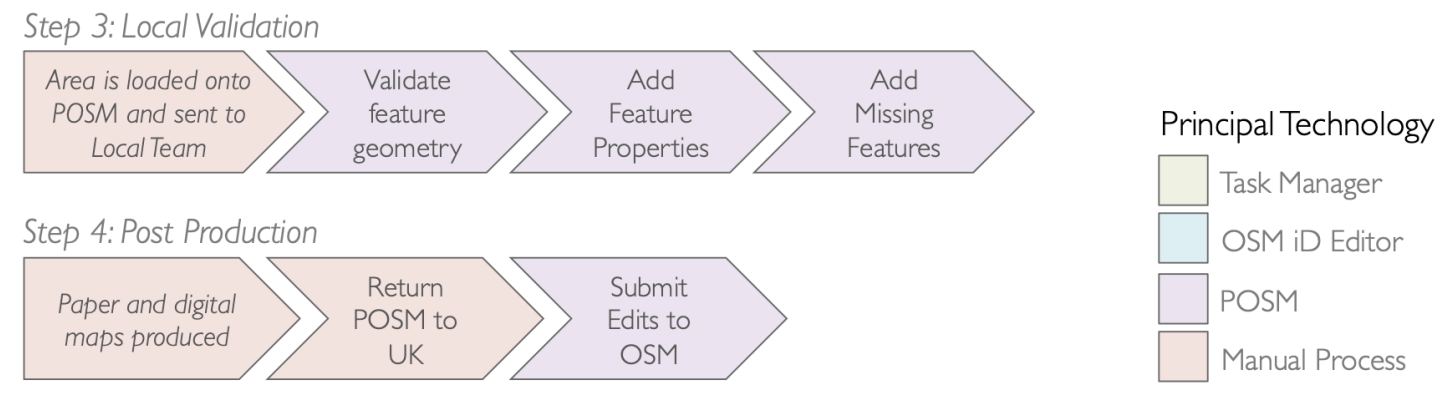

Figure 6: Typical 4-step workflow for VGI map production in this project.

In spite of the relative success of this project (and others like it), it is clear that there are still major challenges to be addressed if our goal of a complete map of the region is to be achieved. The most significant is that Acholi is predominantly very rural with few points of interest, so attracting and motivating volunteers is difficult, and mapping features can be laborious and demoralising. Addressing challenges such as this can be approached either by increasing motivation (e.g. through campaigning, normally as part of a response to a Humanitarian Crisis) or by increasing the efficiency of each volunteer. Despite the success of our project to date, the former solution remains challenging for an area such as Acholi. Our strategy has therefore deployed Centaur VGI techniques to augment the 'digitisation' step in the workflow. Figure 8 compares our workflow to more traditional VGI approaches. 

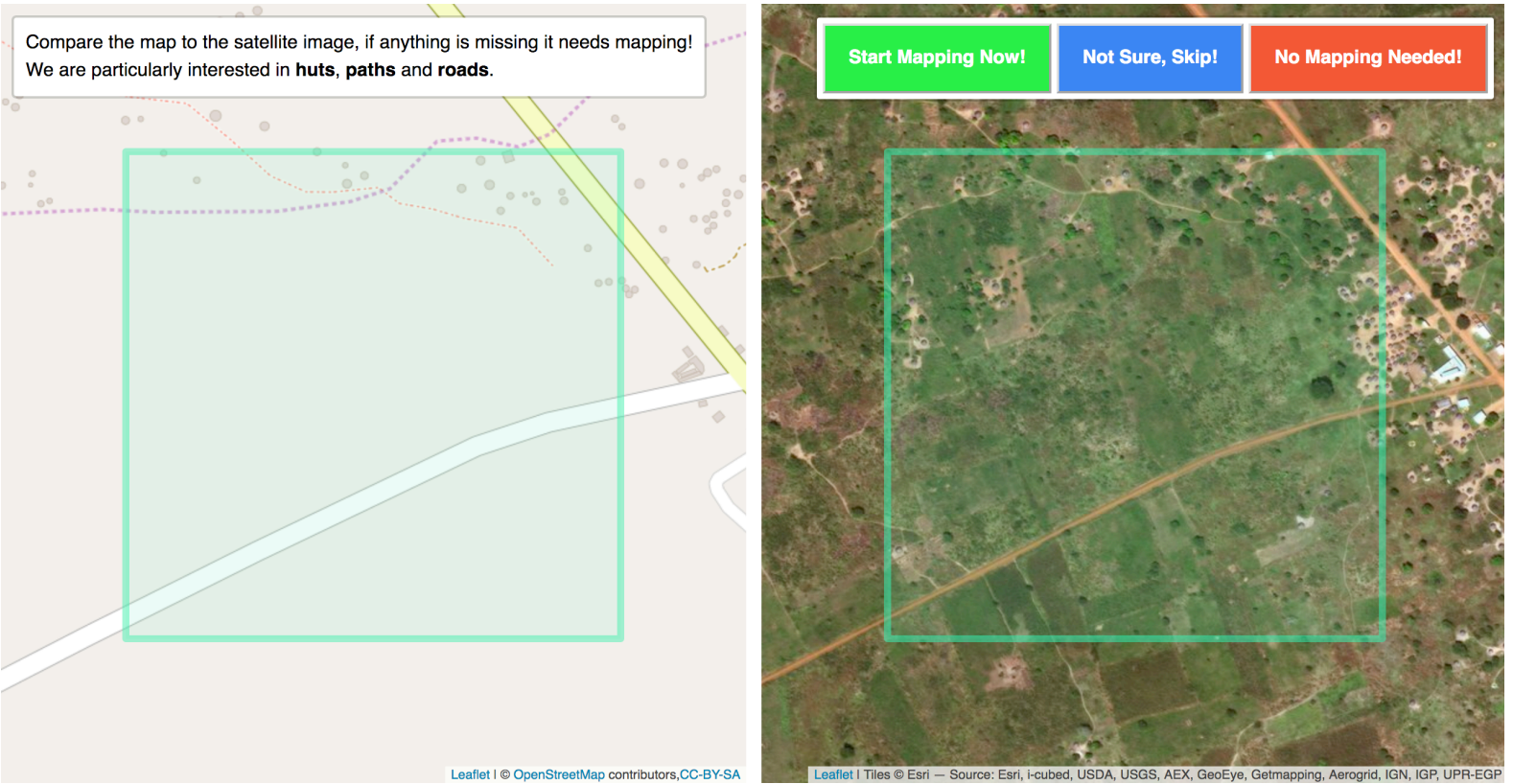

Figure 7: Screenshot of an early version of the 'Huckathon' software used by the project to systematically search for features to be mapped. In colour online.

\section{A: 'Traditional' OSM workflow}

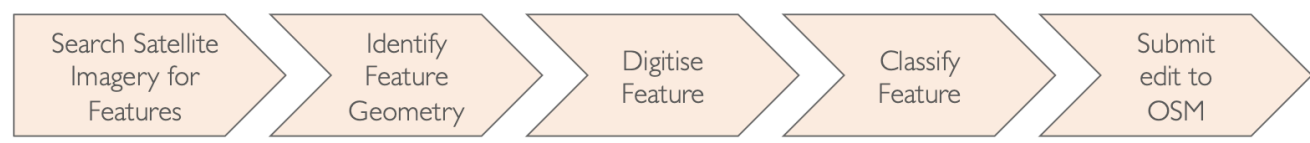

\section{B: CentaurVGl workflow}

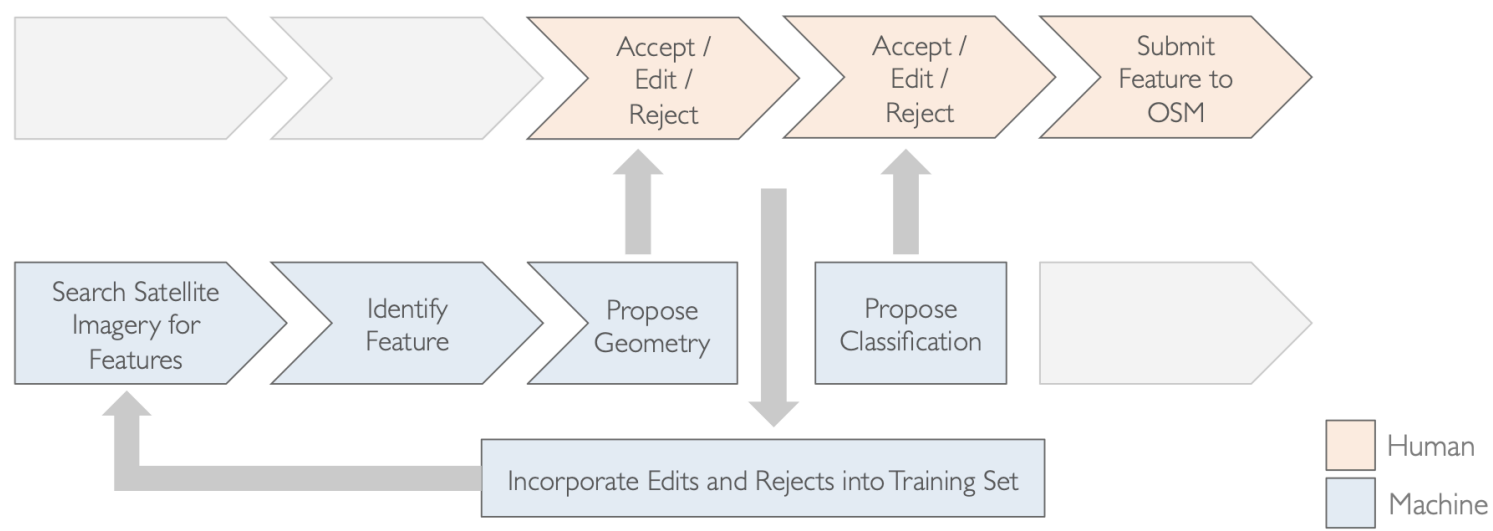

Figure 8: (A) the 'Traditional' OSM feature creation workflow. (B) The alternative centaur VGI workflow (c.f.

Figure 5, Step 1). 
Digitisation (Figure 6, Step 1) can be made more efficient by automating the most time-consuming parts of the process, but leaving decisions to human volunteers. Benefits of such an approach include: increasing the speed of the digitisation per feature (fewer steps for the human to undertake); increasing the quality of the overall dataset (fewer 'clicks per feature' reduces the potential for volunteer fatigue, whilst human approval catches machine errors or inaccuracies); and increasing egocentric motivation through active learning (volunteers can see how their feedback is improving automated aspects of the process relating to their own mapping and that of future volunteers). This is likely to provide intellectual stimulation beyond that which can be achieved through simple manual digitisation. We suggest it is important that the process is as transparent as possible, and that users need to view statistics not only on how many features they have mapped, but also the impact of their feedback upon the machine through illustrative graphics built in to the editing interface.

This paper is intended as an argument and intellectual justification for centaur VGI approaches as a potential solution to VGI mapping inequalities in remote and rural regions of the Global South that might also be compatible with the requirements of the OSM community (which prevent more traditional ML applications from widespread usage). We therefore seek to define the principles and benefits of such a system, rather than to demonstrate or evaluate a particular instance of a system. This is because a centaur VGI platform could use any combination of classification models, location and types of feature to target, map editor (including the option to develop a new one), and approach to feature selection for AL (including the option not to employ AL at all). The specific satellite imagery dataset that is used introduces further challenges, including variable age of imagery in the same scene, cloud coverage and resolution limiting the size of feature that can be mapped. The properties and success of any such system will therefore necessarily depend upon all of these variables, alongside the age, demographic, education level and experience of the volunteers that take part. As such, the evaluation of specific applications cannot provide a comprehensive reflection of the qualities, benefits and limitations of the concept as a whole. 


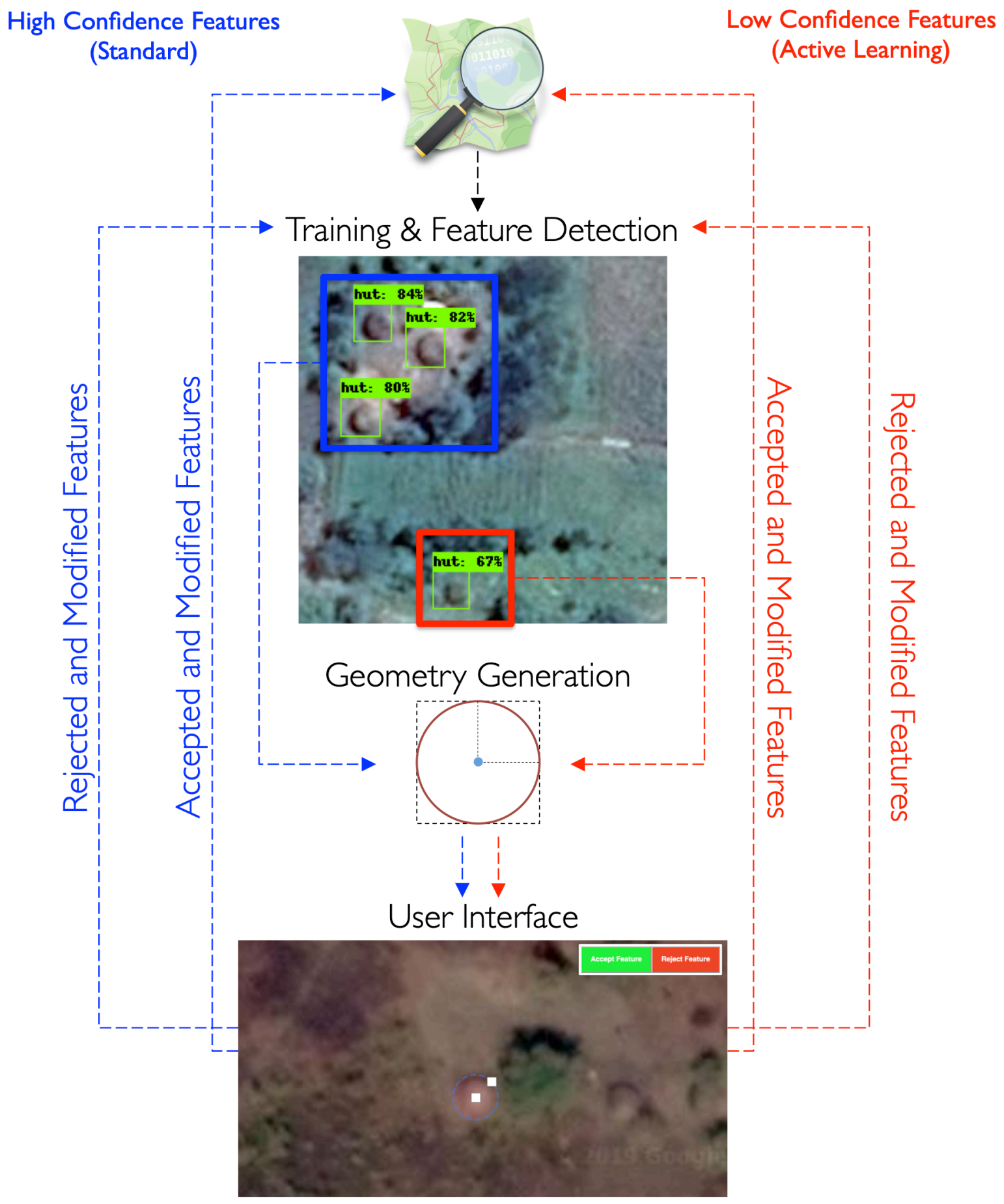

Figure 9: Demonstration interface for a Centaur VGI system (high confidence features in blue and Active Learning for low confidence features in red). Background satellite imagery (C) 2019 Google.

Nevertheless, for the purposes of illustration, we provide a simple example of centaur VGI produced with the intention of identifying huts in image tiles. This exemplar was developed using open source software including Label Maker (Development Seed, 2019) for the production of a training set and the 
Google TensorFlow Object Detection API (Google, 2019) for object detection. Query selection for AL was achieved using max-margin sampling based on the uncertainties reported by the object detection algorithm, with detected features with a reported confidence $<75 \%$ used for this purpose. The use of this system and its components are illustrated in Figure 9, which demonstrates the flow of data through a centaur VGI system with standard (blue) and AL (red) variants demonstrated for features with high and low confidence respectively. Circular hut geometries are generated from the bounding box of the identified feature. The simple interface permits the human volunteer to assess the feature, edit it using the two white handles (one to adjust the position of the feature and one to adjust the radius), and then accept or reject the feature using buttons in the top right of the screen.

This system is intended to demonstrate the principle of centaur VGI; detailed quantitative evaluations of specific implementations are beyond the scope of this article and will be dealt with elsewhere. Projects will have their own priorities in terms of feature types and areas of interest, but approaches such as this have the potential to improve mapping coverage in the parts of the world where coverage is poor, and particularly for features that are small in size and numerous in the landscape, making them repetitive to digitise using traditional approaches.

\section{Conclusions}

Zook et al. (2010) suggest that that there will always be people and communities that are 'left off the map' and that it is important to be aware of these geographical inequalities and ensure that the technologically disconnected are not denied crucial services. Our arguments in this paper have sought to advance understanding of global inequalities in topographical mapping coverage, and to propose an approach to reducing those inequalities through a combination of emergent ML technologies and VGI. To this end, we have presented an argument for centaur VGI as an approach to VGI production that is particularly well suited to the creation of map data for remote, rural, sparsely populated parts of the world that are unlikely to attract sufficient attention from volunteer mappers. Our approach attempts to increase the quality and coverage of data produced in each 'volunteer hour' by developing a hybrid human-machine system to produce synergistic benefits in which the result is superior to its 
component parts. We have started to test these ideas in case research in the Acholi sub-region of northern Uganda, and have presented a simple illustrative implementation of a centaur VGI deployment. Future development of this research will comprise a comprehensive quantitative analysis of centaur VGI applications, exploring the extent and nature of improvements in volunteer efficiency and quality in the context of a variety of applications, models, interfaces, and volunteer groups.

This work complements existing practices in OSM. Existing VGI practices are well established and effective for most parts of the Global North, as well as in response to acute humanitarian crises in many parts of the Global South. This work is therefore intended to focus on remote and rural areas in the Global South that do not suffer with acute humanitarian issues or experience crises that receive international media coverage or organisational prioritisation, leaving them unlikely to be targeted by sufficient volunteers. Nevertheless, whilst these approaches were designed to target areas that are otherwise often overlooked in VGI programmes, they may also have applications in the humanitarian response mapping for areas undergoing acute crises, and in many other areas of VGI production.

The arguments presented in this research have been formulated during an on-going humanitarian research project in the Acholi sub-region of Uganda. Aided by maps produced using a variety of approaches to VGI, including mapathons, local mapping on the ground and early experiments in the centaur VGI approaches, we have successfully delivered the first prevalence study for major limb loss in the region (Okello et al., 2019), an orthopaedic workshop staffed with a team of prosthetists and orthopaedic surgeons, a mobile orthopaedic outreach clinic that travels out to communities to provide care and prosthetic limbs provided free of charge to victims. Future research will include the continuation of these services, the further development and empirical evaluation of the ideas presented in this paper, and the exploration of other ways in which resulting maps may be used in the planning and provision of care, services, infrastructure and humanitarian aid. We are hopeful that the ideas in this paper will contribute to increased mapping coverage and data quality within the Acholi sub-region and elsewhere in the world. It is our vision that the resulting maps will facilitate continued action by local people, government, NGOs and researchers, to help improve health service provision and other vital services such as access to safe drinking water, food, transport and employment. 


\section{Acknowledgements}

This work was supported by the AHRC / MRC GCRF Global Public Health Scheme under Grant AH/R005796/1 and a UKRI GCRF Global Impact Accelerator Grant. We would like to thank Donna Sherman and Nick Scarle for their invaluable help in locating and digitising colonial maps of Uganda, the Huckathon team for enabling the mapathons to take place and the SEED Social Responsibility team at the University of Manchester for their support. We gratefully acknowledge the host of authors of the various open source software projects (referenced throughout this paper) upon which this project relies. Most of all, we thank the Acholi People for their kindness, generosity and friendship.

\section{References}

Akerman, J. R. 2017. Decolonizing The Map: Cartography From Colony To Nation. Chicago: University of Chicago Press.

Anderson, J., D. Sarkar \& L. Palen 2019. Corporate Editors in the Evolving Landscape of OpenStreetMap. ISPRS International Journal of Geo-Information, 8, 232.

Baariu, S. N., G. C. Mulaku, and D. N. Siriba. 2019. State of Cartographic Services among the East African Community Member States. Journal of Geographic Information System 11 (1):56-65.

Bernard, J., M. Hutter, M. Zeppelzauer, D. Fellner \& M. Sedlmair 2018. Comparing visual-interactive labeling with active learning: An experimental study. IEEE Transactions On Visualization And Computer Graphics, 24, 298-308.

Böhme, R. 1991. Inventory of World Topographic Mapping, Volume 2: South America, Central America and Africa. Barking: Elsevier Science Publishers.

Chen, J., Y. Zhou, A. Zipf \& H. Fan 2019. Deep Learning From Multiple Crowds: A Case Study of Humanitarian Mapping. IEEE Transactions on Geoscience and Remote Sensing, 57, 1713-1722. 
Chen, J. \& A. Zipf. 2017. DeepVGI: Deep learning with volunteered geographic information. In Proceedings of the 26th International Conference on World Wide Web Companion, 771-772. International World Wide Web Conferences Steering Committee.

Chinn, M. D. \& R. W. Fairlie 2007. The determinants of the global digital divide: a cross-country analysis of computer and internet penetration. Oxford Economic Papers, 59, 16-44.

Coleman, D., Y. Georgiadou \& J. Labonte 2009. Volunteered geographic information: The nature and motivation of produsers. IJSDIR, 4, 332-358.

Craglia, M., F. Ostermann \& L. Spinsanti 2012. Digital Earth from vision to practice: making sense of citizen-generated content. International Journal of Digital Earth, 5, 398-416.

Crutcher, M. \& M. Zook 2009. Placemarks and waterlines: Racialized cyberscapes in post-Katrina Google Earth. Geoforum, 40, 523-534.

Development Seed 2019. Skynet - machine learning for satellite imagery.

https://developmentseed.org/projects/skynet/. (accessed January 16th 2019).

Disaster Ninja 2019. Disaster Ninja. http://disaster.ninja (accessed October 15th 2019).

Domingues, P. 2017. The Master Algorithm: How the quest for the ultimate learning machine will remake our world. London: Penguin.

Du, B., Z. Wang, L. Zhang, L. Zhang, W. Liu, J. Shen \& D. Tao 2017. Exploring representativeness and informativeness for active learning. IEEE transactions on cybernetics, 47, 14-26.

Elwood, S. 2008. Volunteered geographic information: future research directions motivated by critical, participatory, and feminist GIS. GeoJournal, 72, 173-183.

- - - 2010. Geographic information science: emerging research on the societal implications of the geospatial web. Progress in Human Geography, 34, 349-357. 
Elwood, S., M. F. Goodchild \& D. Z. Sui 2012. Researching Volunteered Geographic Information: Spatial Data, Geographic Research, and New Social Practice. Annals of the Association of American Geographers, 102, 571-590.

Flanagin, A. J. \& M. J. Metzger 2008. The credibility of volunteered geographic information. GeoJournal, 72, 137-148.

Gartner, G., D. A. Bennett \& T. Morita 2007. Towards ubiquitous cartography. Cartography and Geographic Information Science, 34, 247-257.

Gillies, M., R. Fiebrink, A. Tanaka, J. Garcia, F. Bevilacqua, A. Heloir, F. Nunnari, W. Mackay, S. Amershi \& B. Lee. 2016. Human-centred machine learning. In Proceedings of the 2016 CHI Conference Extended Abstracts on Human Factors in Computing Systems, 3558-3565. ACM.

Goodchild, M. F. 2007. Citizens as sensors: the world of volunteered geography. GeoJournal, 69, 211-221.

Goodchild, M. F. \& L. Li 2012. Assuring the quality of volunteered geographic information. Spatial Statistics, 1, 110-120.

Google 2019. Tensorflow. https://www.tensorflow.org/about/ (accessed October 15th 2019).

Graham, M. \& M. Zook 2011. Visualizing Global Cyberscapes: Mapping User-Generated Placemarks. Journal of Urban Technology, 18, 115-132.

Granell, C. \& F. O. Ostermann 2016. Beyond data collection: Objectives and methods of research using VGI and geo-social media for disaster management. Computers, Environment And Urban Systems, 59, 231-243.

Hagen, E. 2010. Putting Nairobi's slums on the map. Development Outreach, 12, 41-43.

Hagenauer, J. \& M. Helbich 2012. Mining urban land-use patterns from volunteered geographic information by means of genetic algorithms and artificial neural networks. International Journal of Geographical Information Science, 26, 963-982. 
Haklay, M. 2010. How good is volunteered geographical information? A comparative study of OpenStreetMap and Ordnance Survey datasets. Environment and Planning B: Planning and Design, $37,682-703$.

Haworth, B.T. 2016. Emergency management perspectives on volunteered geographic information: Opportunities, challenges and change. Computers, Environment and Urban Systems, 57, 189-198.

Haworth, B.T. \& E. Bruce 2015. A review of volunteered geographic information for disaster management. Geography Compass, 9, 237-250.

Haworth, B. T. 2018. Implications of Volunteered Geographic Information for Disaster Management and GIScience: A More Complex World of Volunteered Geography. Annals of the American Association of Geographers, 108, 226-240.

Herfort, B., M. Eckle \& J. P. de Albuquerque. 2016. Being Specific about Geographic Information Crowdsourcing: A Typology and Analysis of the Missing Maps Project in South Kivu. In Proceedings of the ISCRAM 2016 Conference -Rio de Janeiro, Brazil, May 2016.

Herfort, B., H. Li, S. Fendrich, S. Lautenbach \& A. Zipf 2019. Mapping Human Settlements with Higher Accuracy and Less Volunteer Efforts by Combining Crowdsourcing and Deep Learning. Remote Sensing, 11, 1799.

Herfort, B. \& A. Zipf. 2018. Enhancing Crowdsourced Classification on Human Settlements Utilizing Logistic Regression Aggregation and Intrinsic Context Factors. In AGILE 2018. Lund, Sweden.

Holzinger, A. 2016. Interactive machine learning for health informatics: when do we need the humanin-the-loop? Brain Informatics, 3, 119-131.

Huckathon 2019. Huckathon. http://huckathon.org (accessed October 15th 2019).

Humanitarian OpenStreetMap Team 2019. Tasking Manager. https://tasks.hotosm.org/contribute (accessed October 15th 2019). 
Jordan, M. I. \& T. M. Mitchell 2015. Machine learning: Trends, perspectives, and prospects. Science, $349,255-260$.

JOSM 2019. JOSM. https://josm.openstreetmap.dev (accessed October 15th 2019).

Konecny, G., U. Breitkopf, and A. Radtke. 2016. The status of topographic mapping in the world a UNGGIM-ISPRS project 2012-2015. International Archives of the Photogrammetry, Remote Sensing and Spatial Information Sciences-ISPRS Archives 41 (2016) 41:737-741.

Lamwaka. 2016. The Raging Storm: A reporter's inside account of the Northern Uganda War 19862005. Kampala, Uganda: Fountain.

Li, H., B. Herfort \& A. Zipf. 2019. Estimating OpenStreetMap Missing Built-up Areas using Pretrained Deep Neural Networks. In AGILE 2019. Limassol, Cyprus.

Liu, P., H. Zhang \& K. B. Eom 2017. Active deep learning for classification of hyperspectral images. IEEE Journal of Selected Topics in Applied Earth Observations and Remote Sensing, 10, 712-724.

Map with AI 2019. Map With AI. https://mapwith.ai (accessed December 10th 2019).

Norris, J. 2015. Future Trends in geospatial information management: the five to ten year vision. Southampton: Ordnance Survey.

Obermeyer, N. 2007. Thoughts on Volunteered (Geo)-Slavery. NCGIA.

Okello, T. R., S. M. Magada, P. Atim, D. Ezati, A. Campion, E. B. Moro, J. Huck, G. Byrne, A. Redmond \& M. Nirmalan 2019. Major limb loss (MLL): an overview of etiology, outcomes, experiences and challenges faced by amputees and service providers in the post-conflict period in Northern Uganda. Journal of Global Health Reports, 3.

Olteanu-Raimond, A. M., G. Hart, G. M. Foody, G. Touya, T. Kellenberger \& D. Demetriou 2017. The scale of VGI in map production: A perspective on European National Mapping Agencies. Transactions in GIS, 21, 74-90. 
OpenStreetMap, 2019a. Import guidelines. https://wiki.openstreetmap.org/wiki/Import/Guidelines (accessed October 15th 2019).

— — - 2019b. Imports [Mailing List] Archives. https://ists.openstreetmap.org/pipermail/imports/ (accessed October 15th 2019).

- $-2019 \mathrm{c}$. What's the problem with mechanical edits?

https://wiki.openstreetmap.org/wiki/What $\% 27 \mathrm{~s}$ the problem with mechanical edits $\% 3 \mathrm{~F}$ (accessed October 15th 2019).

_ _ 2019d. Imports slated for deletion.

https://wiki.openstreetmap.org/wiki/Import/Catalogue\#Imports_slated_for_deletion

(accessed October 15th 2019).

— — - 2019e. iD. https://wiki.openstreetmap.org/wiki/ID (accessed October 15th 2019).

OSM Analytics 2019. OpenStreetMap Analytics. https://osm-analytics.org/\#/gaps (accessed October 15th 2019).

Parry, B. \& C. Perkins. 2000. World Mapping Today. 2nd ed. Berlin: Walter de Gruyter.

Patra, S. \& L. Bruzzone 2011. A fast cluster-assumption based active-learning technique for classification of remote sensing images. IEEE Transactions on Geoscience and Remote Sensing, 49, $1617-1626$.

Perkins, C. 1987. Map Acquisition. In World Mapping Today, ed. R. B. P. Parry and C.Perkins, 1526. London: Butterworths.

Perkins, C. \& M. Dodge 2009. Satellite imagery and the spectacle of secret spaces. Geoforum, 40, $546-560$.

POSM 2019. Portable OpenStreetMap. https://github.com/posm/posm (accessed October 15th 2019). 
Radcliffe, S. A. 2009. National maps, digitalisation and neoliberal cartographies: transforming nationstate practices and symbols in postcolonial Ecuador. Transactions of the Institute of British Geographers, 34, 426-444.

Scott, G. \& A. Rajabifard 2017. Sustainable development and geospatial information: a strategic framework for integrating a global policy agenda into national geospatial capabilities. Geo-Spatial Information Science, 20, 59-76.

Senaratne, H., A. Mobasheri, A. L. Ali, C. Capineri \& M. Haklay 2017. A review of volunteered geographic information quality assessment methods. International Journal of Geographical Information Science, 31, 139-167.

Settles, B. 2009. Active learning literature survey. Madison, WI: University of Wisconsin-Madison Department of Computer Sciences.

Sharma, M. \& M. Bilgic 2017. Evidence-based uncertainty sampling for active learning. Data Mining and Knowledge Discovery, 31, 164-202.

Smith, N. 2018. Integrating Machine Learning into the Tasking Manager: Notes on a Direction. Humanitarian OpenStreetMap Team.

Stumpf, A., N. Lachiche, J.-P. Malet, N. Kerle \& A. Puissant 2014. Active learning in the spatial domain for remote sensing image classification. IEEE Transactions On Geoscience And Remote Sensing, 52, 2492-2507.

Sui, D., M. Goodchild \& S. Elwood. 2013. Volunteered Geographic Information, the Exaflood, and the Growing Digital Divide. In Crowdsourcing Geographic Knowledge, 1-12. Berlin: Springer.

Thompson, C. 2013. Smarter Than You Think: How technology is changing our minds for the better. London: William Colllins. 
Vargas-Muñoz, J. E., S. Lobry, A. X. Falcão \& D. Tuia 2019. Correcting rural building annotations in OpenStreetMap using convolutional neural networks. ISPRS Journal of Photogrammetry and Remote Sensing, 147, 283-293.

Vinci, A. 2005. The Strategic Use of Fear by the Lord's Resistance Army. Small Wars \& Insurgencies, 16, 360-381.

Yang, L., A. MacEachren, P. Mitra \& T. Onorati 2018. Visually-Enabled Active Deep Learning for (Geo) Text and Image Classification: A Review. ISPRS International Journal of Geo-Information, 7, 65.

Yuan, J., P. K. Roy Chowdhury, J. McKee, H. L. Yang, J. Weaver \& B. Bhaduri 2018. Exploiting deep learning and volunteered geographic information for mapping buildings in Kano, Nigeria. Scientific Data, 5, 180217.

Zhu, X. X., D. Tuia, L. Mou, G.-S. Xia, L. Zhang, F. Xu \& F. Fraundorfer 2017 Deep learning in remote sensing: A comprehensive review and list of resources. IEEE Geoscience and Remote Sensing Magazine, 5, 8-36.

Zielstra, D. \& A. Zipf. 2010. A comparative study of proprietary geodata and volunteered geographic information for Germany. In 13th AGILE International Conference On Geographic Information Science.

Zook, M., M. Graham, T. Shelton \& S. Gorman 2010. Volunteered Geographic Information and Crowdsourcing Disaster Relief: A Case Study of the Haitian Earthquake. World Medical \& Health Policy, 2, 7-33.

\section{Author Biographies}

Jonny Huck is a Lecturer in Geographical Information Science at the University of Manchester, UK and Hon. Professor of Geographical Information Science at Gulu University, Uganda. He is interested in the application of maps and emergent technologies to geographical problems, particularly in the 
areas of health and conflict. In 2017 he founded Community Mapping Uganda (http://communitymapping.co.uk) to produce maps and provide map-based humanitarian services in Northern Uganda.

Chris Perkins is Hon Reader in Geography at the University of Manchester, where he has taught since 1998, having previously run the University's map libraries. His research interests lie at the interface between mapping technologies and social and cultural practices, with on-going research into performative aspects of contemporary mapping behaviour, an interest in sensory mapping, and an emerging interest in play. Chris was Chair of the International Cartographic Association Maps and Society Research Commission and is author of twelve single and co-authored books and numerous academic articles.

Billy Tusker Haworth is a geographer and Lecturer in Geographical Information Systems (GIS) and Disaster Management in the Humanitarian and Conflict Response Institute (HCRI) at the University of Manchester. They teach international disaster management and critical studies of GIS. Billy's research interests include critical GIScience, participatory mapping, marginality and vulnerability, volunteered geographic information (VGI), citizen science, queer geographies, graffiti, and spatial knowledge production.

Emmanual Moro is an Associate Professor of Surgery and Former Dean of the Faculty of Medicine at Gulu University and Fellow of the College of Surgeons of East, Central and Southern Africa. He is interested in Social Transformation through Educational and Health Research and Innovations.

Mahesh Nirmalan is Vice Dean for Social Responsibility and Public Engagement in the Faculty of Biology, Medicine and Health at the University of Manchester, UK. He is Professor of Medical Education and Training at the University of Manchester, UK; and Hon. Professor of Post Conflict studies at Gulu University, Uganda 